\title{
The perception of smile attractiveness among Saudi population
}

This article was published in the following Dove Press journal:

Clinical, Cosmetic and Investigational Dentistry

20 January 2015

Number of times this article has been viewed

\section{Hadeel A Mokhtar \\ Layla W Abuljadayel \\ Reem M Al-Ali \\ Mohammed Yousef}

Department of Operative Dentistry, Faculty of Dentistry, King Abdulaziz University, Jeddah, Saudi Arabia
Correspondence: Mohammed K Yousef Department of Operative Dentistry, Faculty of Dentistry, King Abdulaziz University, PO Box 80209, Jeddah, 21589, Saudi Arabia

Email myousf@kau.edu.sa
Abstract: Parameters of dental beauty change across time for varying reasons. Thus, an understanding of the factors that help or harm the attractiveness of a smile is an important step in creating attractive smiles. This study aimed to identify factors that affect smile perception and attractiveness among the Saudi population. A cross-sectional study was conducted among the Saudi population. Questionnaires were distributed to 130 dentists and final-year dental students, and to 130 laypersons. The questionnaire contained six smile photographs created by Photoshop ${ }^{\mathbb{R}}$ software. There was a statistically significant difference in scale ratings, based on participant background, for the "gummy" smile picture $(P$-value $=0.003)$, diastema picture $(P$-value $=0.000)$ and the "Reverse" smile picture $(P$-value $=0.004)$. As for sex, males significantly underscored the gummy picture $(P$-value $=0.009)$. Older people accepted the gummy smile less than did younger people, but diastema was considered as one of the variations that spoiled the attractiveness of the smile. "Dental background" participants significantly identified the ideal smile better than the "nondental" group. The perception of diastema as a sign of beauty among Saudi population in the past has definitely changed, according to the results of our study, where diastema and reverse smile received the lowest score in this survey.

Keywords: diastema, gummy, reverse

\section{Introduction}

People's concern about the beauty and attractiveness of their teeth began more than 2,000 years ago. ${ }^{1}$ Some ancient Asians intentionally stained their teeth black or inlayed them with precious stones as signs of nobility, while first-century Romans brushed their teeth with urea to give them whiter teeth. ${ }^{1}$ The cultural definition of dental beauty differs, however, across different populations, regions, countries, and even continents. It is also dynamic, with parameters of dental beauty changing across time, for varying reasons. For example, in the 1960s and 1970s diastema was considered a sign of beauty, but nowadays, most seek dental treatment for diastema closure. ${ }^{2}$

In recent years, preoccupation about cosmetic dentistry has increased. This is due to media exposure, to the extent that people now demand to have their teeth resemble their favorite actor or actress, or even their popular leader or politician.

People nowadays are concerned about the appearance and attractiveness of their teeth and about exploring options for further cosmetic treatment. Thus, an understanding of factors that help or harm the attractiveness of a smile is important in creating attractive smiles. Study of beauty standards and norms is done to guarantee that clinicians can create the desirable "golden smile" with the application of these norms and standards to diagnostic methods and esthetic treatment plans. ${ }^{1}$ 
A study by Dunn et al concluded that tooth shade was the most important factor for an esthetic smile, followed in sequence by the presence of natural teeth, without restorations and number of teeth displayed. ${ }^{2}$ Among the factors that can affect the smile attractiveness is the degree of midline shift. Pinho et al found that a $1 \mathrm{~mm}$ shift can be perceived by orthodontists and a $3 \mathrm{~mm}$ shift by prosthodontists, while laypersons did not notice the midline shift less than $4 \mathrm{~mm}$. Furthermore, orthodontists, prosthodontists, and laypersons had different perceptions of smile esthetics when evaluating maxillary incisors and gingival exposure. ${ }^{3}$

An ideal smile may not exist, but the most important esthetic objective is achieving a balanced smile, which can be described as an adequate positioning of teeth, including positioning with respect to gingival soft tissues. ${ }^{4}$

Our study planned to assess perceptions of smile attractiveness among the Saudi population, in the coastal city of Jeddah, Saudi Arabia. The study also evaluated patients' knowledge and background regarding their perception of perfect or ideal smile.

\section{Materials and methods Smile photographs}

A cross-sectional study was conducted among 260 Saudi participants, 130 laypersons and 130 dental professionals, in June 2013, at the Faculty of Dentistry in King Abdulaziz University in Jeddah, Saudi Arabia. Two pictures of an ideal smile (mouth only), one of an "Ideal Male" (IM) smile (Figure 1) $)^{5}$ and the other of an "Ideal Female" (IF) (Figure 2), were taken from the Internet. These pictures were chosen according to the following selection criteria: 1) high degree of attractiveness, and 2) characteristics close to "textbook" norms. ${ }^{6,7}$

Laypersons included patients in the dental school and medical students within the campus of King Abdulaziz University, Faculty of Medicine. As for the dental professionals, these

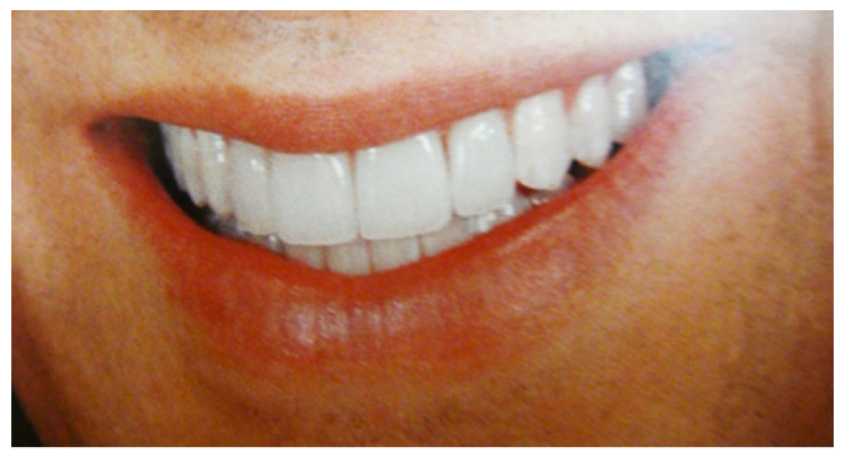

Figure I Ideal male smile.

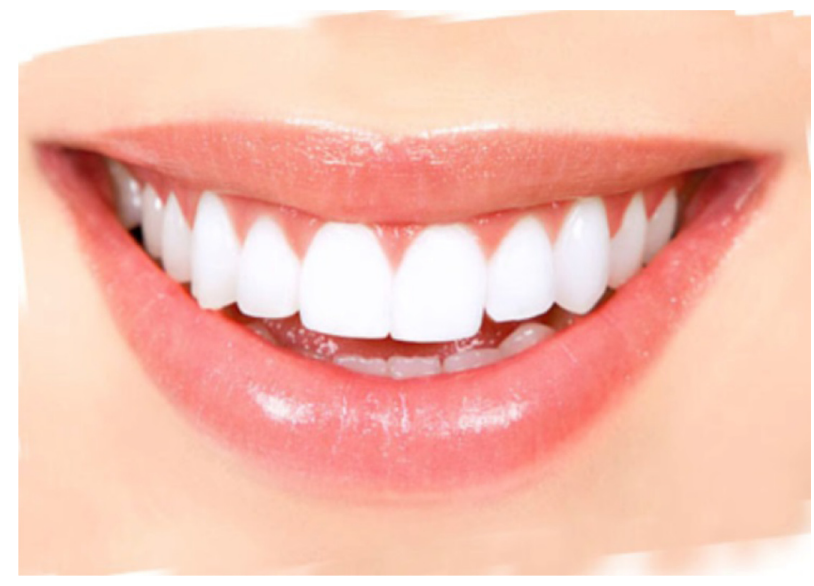

Figure 2 Ideal female smile.

were dentists and dental students in their final year of study. All the pictures were evaluated for both groups.

The IF smile was digitally manipulated using Adobe Photoshop ${ }^{\circledR}$ CS4 software to give it the selected norms of beauty. The IF smile (Figure 2) thereby created served as a control and "golden" model for the rest of the photographs; afterwards, the IF smile was used to make further digital manipulations, ie, to create a smile with variations from esthetic norms.

These variations were:

1. "Gummy" smile (G), for which the gingival distance was increased to become $5 \mathrm{~mm}$ from the gingival margin of anterior teeth to the lower lip line of upper lip (Figure 3)

2. Smile with diastema (D), for which a $1 \mathrm{~mm}$-wide diastema was created between the maxillary incisors only (Figure 4)

3. Smile with midline deviation (ML), for which the dental midline was shifted $3 \mathrm{~mm}$ in relation to the patient's philtrum (Figure 5)

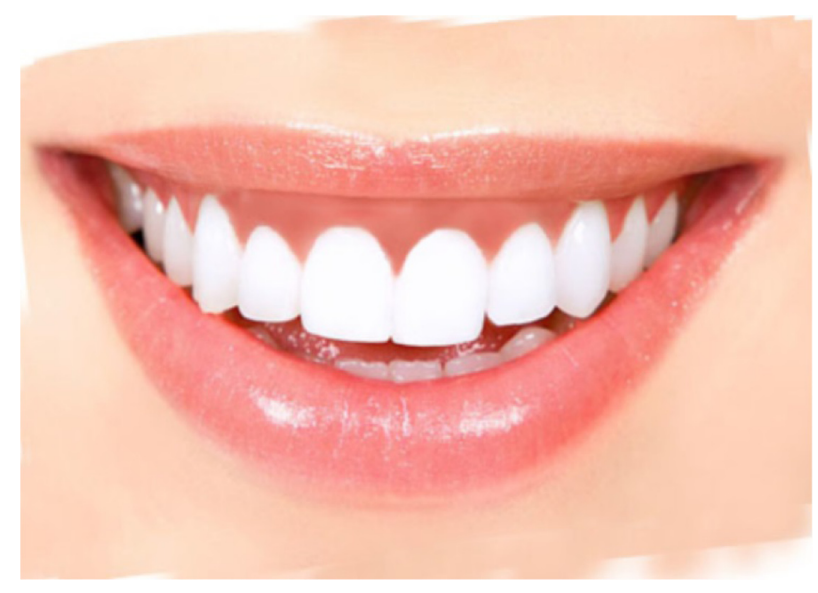

Figure 3 Gummy smile. 


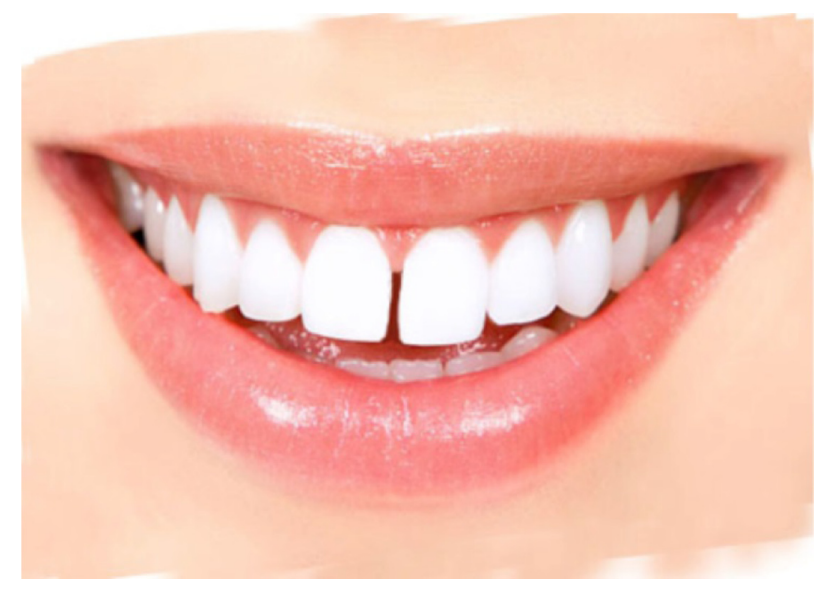

Figure 4 Smile with diastema.

4. "Reverse" smile (R), for which the maxillary central and lateral incisal borders were repositioned more apically, creating the contour of an inverted parabola (Figure 6).

\section{The questionnaire}

The questionnaire consisted of three parts:

1. Part 1 elicited demographic data of the participant, to determine nationality, sex, age, and dental background

2. Part 2 consisted of the photograph page, where the photographs were coded from 1 to 6

3. Part 3, found on the page opposing the photographs, consisted of 14 questions, where the evaluator was asked to rank each smile using a scale of 1 to 5 (where 1 was the worst and 5 was the best) and to answer questions that described size, shape, position of teeth, and degree of gingival showing of each smile, as well as two questions about treatment of $\mathrm{D}$ and $\mathrm{G}$.

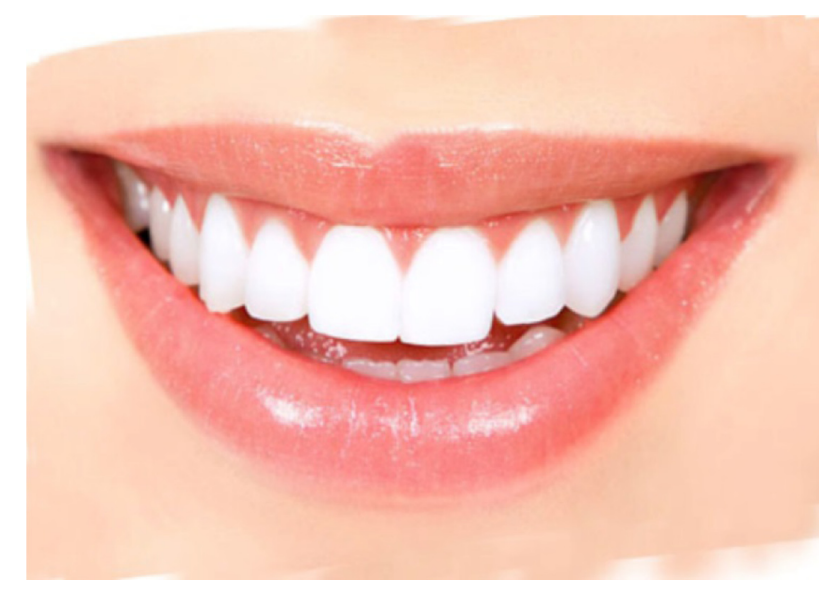

Figure 5 Smile with midline deviation.

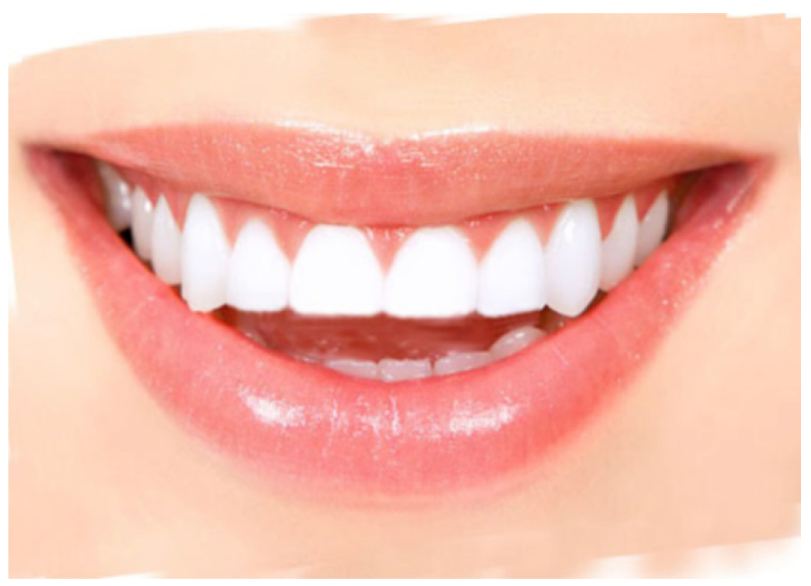

Figure 6 Smile with reverse smile arc

\section{Evaluation of the photographs}

A total 130 "nondental background" persons from King Abdulaziz University (KAAU) campus (patients in dental clinics waiting area, medical students) and 130 "dental background" persons (dentists and senior dental students at King Abdulaziz University) agreed to complete our survey, to evaluate the photographs and answer the attached questions.

The criteria for selection of the participants were:

1. Saudi nationality

2. Age 18 years old or older

3. Voluntary agreement to participate in the study for evaluation of the photographs.

\section{Statistical analysis}

The study used Statistical Package for Social Science (SPSS), version 18. Aside from descriptive statistics, this study used Chi-square test in establishing the relationship between variables. In comparing two group means and multiple group means, independent $t$-test and one-way analysis of variance (ANOVA) was used, respectively.

While Levene's test was used to check for normality, post hoc test (Games-Howell) was used when there was no normal distribution. A 5\% level of significance was used, with $P$-value $<0.05$.

\section{Results}

The 248 Saudi respondents were nearly equally divided into two groups (120 laypersons, 128 with dental background). The IF picture was scored the highest for attractiveness, while the $\mathrm{D}$ picture had the lowest score.

\section{Background (dental vs nondental)}

There was a statistically significant difference in the scale ratings, based on participant background, for the $\mathrm{G}$ picture 
$(P$-value $=0.003), \mathrm{D}$ picture $(P$-value $=0.000)$ and $\mathrm{R}$ picture $(P$-value $=0.004)$. Table 1 shows that dentists scored these pictures poorly compared with laypersons.

\section{Age}

There were three age groups (18-30, 31-40, 40 and above years). For all the age groups, there was no significant difference in evaluation for four of the pictures (IM, IF, ML, and $\mathrm{R}$ ), while there was a significant difference in evaluation of the $\mathrm{G}$ picture $(P$-value $=0.039)$ Table 2 and $\mathrm{D}$ picture ( $P$-value $=0.022)$; we found that older people (more than 40 years) accepted gummy smile less than did younger people (18-30 years), and middle-aged people (31-40 years) accepted diastema more than did younger people, but diastema was considered as a variation that spoiled the attractiveness of a smile and took the lowest score among all age groups. Mean scores on the survey scale for the different smile pictures, according to age of the respondents, are shown in Table 2.

\section{Sex}

Males significantly underscored the G picture $(P$-value $=0.009)$ compared with females $(P$-value $=0.057)$. Mean scores on the survey scale for the different smile pictures, according to sex of respondents, are shown in Table 3.

\section{Treatment}

\section{Treatment of gummy smile}

\section{Background}

There was a significant difference in ratings of the need to treat gummy smile between the two groups $(P$-value $=0.001)$ : $66.2 \%$ (26.3\% laypersons, $39.9 \%$ dentists) thought that treatment of gummy smile was mandatory for smile esthetics, while $33.8 \%$ (21.7\% laypersons, $12.1 \%$ dentists) thought there was no need for treatment and that it was considered as a sign of beauty.

\section{Age and sex}

There was no significant difference among all age groups, or males and females of both groups, for the treatment of gummy smile as they equally considered that treatment was mandatory for smile esthetic and beauty.

\section{Treatment of diastema \\ Background}

There was no significant difference in ratings of the need to treat diastema between the two groups $(P$-value $=0.083$ ): $80.6 \%$ (37\% laypersons, $43.6 \%$ dentists) thought that treatment of diastema and closing of the gap between teeth was mandatory for smile esthetics, while 19.4\% (11.8\% laypersons, $7.6 \%$ dentists) thought there was no need for that kind of treatment.

\section{Age and sex}

There was no significant difference among all age groups, or males and females of both groups, for the treatment of diastema as they equally considered that treatment was mandatory for smile esthetics and beauty.

\section{Discussion}

Background, age, and sex, among other factors, have been considered to influence Saudi people's perceptions of smile attractiveness. There are many factors that can contribute to smile attractiveness. A few studies have suggested that tooth color is a significant factor in the attractiveness of a smile. ${ }^{8-10}$ In our study, we assessed other important factors, such as smile line and form, gingival aesthetics, center line, symmetry and midline, incisal plane, proportion, and axial alignment.

The present study shows that there was a statistically significant difference in evaluation of gummy, reverse, and diastema smiles among the Saudis, according to participant background, age, and sex.

When observing the perception of pictures with variation from esthetic norms on the attractiveness of a smile, we found that the IF and IM smile generally received good evaluations from both groups (dentists and laypersons), which suggests that it is valid to use the ideal smile as a reference when constructing an attractive and beautiful smile.

The ML smile image got positive evaluation from both groups (dentists and laypersons), while the G image got positive evaluation from large numbers of laypersons only, which means that planning esthetic treatment to obtain a

Table I Percentages of dental personnel and laypersons answering "yes" that they liked the picture (scoring $\geq 4$ on the survey scale)

\begin{tabular}{lllllll}
\hline Pictures & $\begin{array}{l}\text { Ideal male } \\
\text { smile }\end{array}$ & $\begin{array}{l}\text { Ideal female } \\
\text { smile }\end{array}$ & $\begin{array}{l}\text { Gummy } \\
\text { smile }\end{array}$ & $\begin{array}{l}\text { Diastema } \\
\text { smile }\end{array}$ & $\begin{array}{l}\text { Midline shift } \\
\text { smile }\end{array}$ & $\begin{array}{l}\text { Reverse } \\
\text { arc smile }\end{array}$ \\
\hline Lay person & 74 & 93 & $59 *$ & $20^{*}$ & 66 & $20^{*}$ \\
Dental background & 65 & 92 & 30 & 14 & 64 & 11 \\
\hline
\end{tabular}

Note: *Indicates significant difference. 
Table 2 Mean score of survey scale of different smile pictures, according to age of respondents

\begin{tabular}{|c|c|c|c|c|c|c|}
\hline Age & $\begin{array}{l}\text { Ideal male } \\
\text { smile scale }\end{array}$ & $\begin{array}{l}\text { Ideal female } \\
\text { smile scale }\end{array}$ & $\begin{array}{l}\text { Gummy } \\
\text { smile scale }\end{array}$ & $\begin{array}{l}\text { Diastema } \\
\text { smile scale }\end{array}$ & $\begin{array}{l}\text { Midline shift } \\
\text { smile scale }\end{array}$ & $\begin{array}{l}\text { Reverse arc } \\
\text { smile scale }\end{array}$ \\
\hline \multicolumn{7}{|c|}{$18-30$ yrs } \\
\hline $\mathrm{N}$ & 207 & 204 & 206 & 202 & 203 & 204 \\
\hline Mean & 3.47 & 4.48 & 3.18 & $2.04 *$ & 3.85 & 2.24 \\
\hline \multicolumn{7}{|c|}{$31-40$ yrs } \\
\hline $\mathrm{N}$ & 24 & 24 & 24 & 23 & 23 & 24 \\
\hline Mean & 3.37 & 3.83 & 3.25 & $3.00 *$ & 3.52 & 3.00 \\
\hline \multicolumn{7}{|l|}{$>40 \mathrm{yrs}$} \\
\hline$N$ & 11 & 11 & II & 11 & 11 & 11 \\
\hline Mean & 3.09 & 3.73 & $2.45^{*}$ & 2.55 & 3.45 & 2.45 \\
\hline \multicolumn{7}{|l|}{ Total } \\
\hline $\mathrm{N}$ & 242 & 239 & $24 I$ & 236 & 237 & 239 \\
\hline
\end{tabular}

Notes: *Indicates significant difference. Scale of I to 5 (where I was the worst and 5 was the best).

harmonious smile doesn't necessitate correcting all variations from esthetic norms. On the other hand, Kokich et al found that asymmetric alterations make teeth more unattractive to, not only dental professionals but also, the lay public. Laypeople perceived a change in attractiveness when the distance from gingiva to lip was $3.0 \mathrm{~mm}$ or greater. However, dentists did not rate excess gingival display as unattractive, even with a maximum of $4.0 \mathrm{~mm}$. The general dentists had a higher threshold. ${ }^{11}$

Geron and Atalia stated that gingival exposure was an unaesthetic feature, especially in the lower arch and above $1 \mathrm{~mm}$ in the upper. Any level of lower gingival display below the mandibular incisor crowns was considered unacceptable. However, because the amount of gingival display that is acceptable esthetically can vary widely, the patient's view and preferences should be the major parameter in the decision-making process of treatment planning. ${ }^{12}$

Dong et al concluded that the low scoring of images with exposure of lower teeth and gingiva could be expected because exposure of lower teeth and gingiva is a sign of aging. ${ }^{13}$ A few studies concluded that with aging, less of the maxillary anterior teeth show, ${ }^{14,15}$ and with loss of tonicity in the facial muscles, the lip will move less. ${ }^{16,17}$ So, as people get older, they show less gingiva on smiling.
Treatment of gummy smile is further emphasized by the effect of aging on gingival display and probably, sex difference. According to van der Geld and van Waas' literature search, ${ }^{18}$ it appears that the smile line is, on average, situated higher among women than among men.

van der Geld et al found that the size of teeth, their visibility, and upper lip position are critical factors in self-perception of smile attractiveness in different cultures. Color of teeth and gingival display are critical factors in self-satisfaction with smile appearance. Smiles with disproportional gingival display are judged negatively and correlate with personality characteristics. ${ }^{19}$

Pinho et al found that laypersons, orthodontists, and prosthodontists had different perceptions of attractiveness when evaluating gingival margin height of a maxillary central incisor and a dental midline shift. The threshold of the orthodontists and the prosthodontists for asymmetry of the gingival margin of a maxillary central incisor was $0.5 \mathrm{~mm}$; the threshold for laypersons, who were less perceptive, was $2.0 \mathrm{~mm} .^{3}$ This is in contrast to our study, where we found that a large number of laypersons did not rate excess upper gingival display as unattractive, even with the maximum $5.0 \mathrm{~mm}$ in relation to the patient's philtrum. In addition, $21.7 \%$ laypersons and $12.1 \%$ dentists thought that there was

Table 3 Mean score of survey scale of different smile pictures, according to sex of respondents

\begin{tabular}{|c|c|c|c|c|c|c|}
\hline Sex & $\begin{array}{l}\text { Ideal male } \\
\text { smile scale }\end{array}$ & $\begin{array}{l}\text { Ideal female } \\
\text { smile scale }\end{array}$ & $\begin{array}{l}\text { Gummy } \\
\text { smile scale }\end{array}$ & $\begin{array}{l}\text { Diastema } \\
\text { smile scale }\end{array}$ & $\begin{array}{l}\text { Midline shift } \\
\text { smile scale }\end{array}$ & $\begin{array}{l}\text { Reverse arc } \\
\text { smile scale }\end{array}$ \\
\hline \multicolumn{7}{|l|}{ Male } \\
\hline$N$ & 120 & 119 & 120 & 118 & 118 & 119 \\
\hline Mean & 3.50 & 4.24 & $2.95 *$ & $2.16 *$ & 3.89 & $2.16 *$ \\
\hline \multicolumn{7}{|l|}{ Female } \\
\hline $\mathrm{N}$ & 123 & 121 & 122 & 119 & 120 & $12 \mid$ \\
\hline Mean & 3.40 & 4.50 & 3.34 & $2.16 *$ & 3.73 & $2.45^{*}$ \\
\hline
\end{tabular}

Note: *Indicates significant difference. 
no need to treat gummy smile as this variant did not spoil the attractiveness of the smile, while $26.3 \%$ laypersons and $39.9 \%$ dentists considered treatment of gummy smile was important for smile esthetic and beauty, suggesting that dentists have higher awareness of gummy smile than laypersons. In taking a clinical decision, we should consider type and degree of deviation, patient opinion, and expectation, invasiveness of the procedure, and cost of treatment.

Evaluation of smile esthetics was very much dependent on sex. In our study, we found that male participants gave statistically significant lower scores than did female participants, to the G image. This is in agreement with the Geron and Atalia study, which found that female participants gave statistically significant higher scores than male participants to upper gingival exposure smiles, suggesting that females are more tolerant of upper gingival exposure. Also, female images were given statistically significant lower scores than were the same male images, by both male and female participants, suggesting that additional efforts should be taken in female patients to achieve an esthetic result. ${ }^{12}$

In our study, we found that diastema (D image) and reverse arc ( $\mathrm{R}$ image) spoiled the attractiveness of the smile and drew the lowest scores of all the pictures. The low scoring of the D image was probably due to violation of the esthetic principle of unity, and to the principle of harmony and balance in the case of the $\mathrm{R}$ image. Dentists and laypersons of different ages and sex thought that treatment of $1 \mathrm{~mm}$ diastema was necessary for smile esthetics and beauty, while Kokich et al found that dentists and laypeople did not rate a midline diastema as unattractive until the distance between the contacts of the central incisors was $2.0 \mathrm{~mm} .{ }^{11}$ Studies have shown that a smile that creates a sense of unity is considered more attractive. ${ }^{14-20}$ Other studies concluded that the principle of unity is more important than other esthetic principles in the determination of the attractiveness of a smile. ${ }^{20,21}$ Regarding the D image, it is important to mention the high standard deviation of the mean score. ${ }^{1}$ This means that for some of the participants, the presence of this deviation does not harm the attractiveness of the smile. ${ }^{1}$ The clinical significance is that the elimination of a diastema should be discussed with patients; in general, though, the presence of a diastema reduces the esthetic appeal of a smile. ${ }^{1}$

\section{Conclusion}

We found that:

- "Dental background" participants significantly identified the ideal smile better than laypersons
- Diastema smile and reverse smile were regarded as unattractive and received the lowest score in this survey

- Regarding the background, age, and sex, there was no significant difference in the ratings of the need to treat diastema: dentists and laypersons thought that treatment of diastema and closing the gap between teeth was mandatory for smile esthetics and beauty

- Gummy smile was scored unattractive by $70 \%$ dentists and $41 \%$ laypersons, suggesting that dentists have higher awareness of gummy smile than do laypersons

- The presence of midline shift was not considered unaesthetic up to $3 \mathrm{~mm}$, so the complicated type of treatment to correct this acceptable deviation is unnecessary.

\section{Acknowledgment}

The authors would like to thank Dr Abdulraheem Al-Wafi and Dr Abdulkadir Bukhari for their valuable efforts in data collection.

\section{Disclosure}

The authors report no conflicts of interest in this work.

\section{References}

1. Rodrigues Cde D, Magnani R, Machado MS, Oliveira OB. The perception of smile attractiveness. Angle Orthod. 2009;79(4):634-639.

2. Dunn WJ, Murchison DF, Broome JC. Esthetics: patients' perceptions of dental attractiveness. J Prosthodont. 1996;5(3):166-171.

3. Pinho S, Ciriaco C, Faber J, Lenza MA. Impact of dental asymmetries on the perception of smile esthetics. Am J Orthod Dentofacial Orthop. 2007;132(6):748-753.

4. Ritter DE, Gandini LG Jr, Pinto Ados S, Ravelli DB, Locks A. Analysis of the smile photograph. World J Orthod. 2006;7(3):279-285.

5. Goldstein RE. Change Your Smile: Discover How a New Smile Can Transform Your Life. 4th ed. Chicago, IL: Quintessence Publishing Co, Ltd; 2009.

6. Rufenacht CR. Fundamentals of Esthetics. 2nd ed. Chicago, IL: Quintessence Publishing Co, Ltd; 1990.

7. Roberson TM, Heymann HO, Swift EJ. Sturdevant's Art and Science of Operative Dentistry. 5th ed. St. Louis, MO: Mosby Inc.; 2006.

8. Kihn PW. Vital tooth whitening. Dent Clin NorthAm. 2007;51(2):319-331, viii.

9. Vivek S, Vikas P, Meenakshi K, Sandhya P, Rao Lakshmana B. A study of relationship between skin color and tooth shade value in Population of Udaipur, Rajasthan. International Journal of Dental Clinics. 2010;2(4):26-29.

10. Rehman K, Khan FR, Rahman M. Assessing the perception of smile attractiveness in young adults: A pilot study. J Pak Dent Assoc. 2011;20(4):206-210.

11. Kokich VO, Kokich VG, Kiyak HA. Perceptions of dental professionals and laypersons to altered dental esthetics: asymmetric and symmetric situations. Am J Orthod Dentofacial Orthop. 2006;130(2):141-151.

12. Geron S, Atalia W. Influence of sex on the perception of oral and smile esthetics with different gingival display and incisal plane inclination. Angle Orthod. 2005;75(5):778-784.

13. Dong JK, Jin TH, Cho HW, Oh SC. The esthetics of the smile: a review of some recent studies. Int J Prosthodont. 1999;12(1):9-19. 
14. Lombardi RE. The principles of visual perception and their clinical application to denture esthetics. J Prosthet Dent. 1973;29(4):358-382.

15. Vig RG, Brundo GC. The kinetics of anterior tooth display. J Prosthet Dent. 1978;39(5):502-504.

16. Mackley RJ. An evaluation of smiles before and after orthodontic treatment. Angle Orthod. 1993;63(3):183-189; discussion 190.

17. Janzen EK. A balanced smile - a most important treatment objective. Am J Orthod. 1977;72(4):359-372.

18. van der Geld PA, van Waas MA. [The smile line, a literature search]. Ned Tijdschr Tandheelkd. 2003;110(9):350-354. Dutch.
19. Van der Geld P, Oosterveld P, Van Heck G, Kuijpers-Jagtman AM. Smile attractiveness. Self-perception and influence on personality. Angle Orthod. 2007:77(5):759-765.

20. Valo TS. Anterior esthetics and visual arts: beauty, elements of composition, and their clinical application to dentistry. Curr Opin Cosmet Dent. 1995;3:24-32.

21. Sarver DM. The importance of incisor positioning in the esthetic smile: the smile arc. Am J Orthod Dentofacial Orthop. 2001;120(2):98-111.

\section{Publish your work in this journal}

Clinical, Cosmetic and Investigational Dentistry is an international, peer-reviewed, open access, online journal focusing on the latest clinical and experimental research in dentistry with specific emphasis on cosmetic interventions. Innovative developments in dental materials, techniques and devices that improve outcomes and patient satisfaction and preference will be highlighted. The manuscript management system is completely online and includes a very quick and fair peerreview system, which is all easy to use. Visit http://www.dovepress. com/testimonials.php to read real quotes from published authors.

Submit your manuscript here: http://www.dovepress.com/clinical-cosmetic-and-investigational-dentistry-journal 